\title{
ENVIRONMENTAL TOBACCO SMOKE EXPOSURE AND THE IMPACT OF A SMOKING BAN IN INTERNET CAFES, PUBS AND BILLIARD HALLS AROUND A UNIVERSITY IN KOREA
}

\author{
KWONCHUL HA ${ }^{1} \&$ DONGUK PARK ${ }^{2}$ \\ ${ }^{1}$ Department of Biochemistry \& Health Science, Changwon National University, South Korea \\ ${ }^{2}$ Department of Environmental Health, Korea Open National University, South Korea
}

\begin{abstract}
The objectives of this study were to determine indoor levels of environmental tobacco smoke (ETS) and assess the implementation rate of a smoking ban in hospitality venues surrounding a university campus by measuring particulate matter smaller than $2.5 \mu \mathrm{m}\left(\mathrm{PM}_{2.5}\right)$ as an indicator of ETS. We identified the smoking state in business establishments and measured the indoor $\mathrm{PM}_{2.5}$ concentrations at 20 internet cafes, 38 pubs and 20 billiard halls using a Sidepak AM510 direct-reading portable real-time monitor from October 2014 to December 2015. Smoking was observed in 65\% of the internet cafes and $85 \%$ of the billiard halls in 2015. The rate in pubs, which were subject to a legal smoking ban, was reduced to $10 \%$ in 2015 from $33.3 \%$ in 2014. The average $\mathrm{PM}_{2.5}$ concentrations in 2015 were $98.6 \mu \mathrm{g} / \mathrm{m}^{3}, 29.6 \mu \mathrm{g} / \mathrm{m}^{3}$ and $135.4 \mu \mathrm{g} / \mathrm{m}^{3}$ in internet cafes, pubs and billiard halls, respectively. $\mathrm{PM}_{2.5}$ concentrations in internet cafes and billiard halls were 2 to 2.7 times higher than the 24-h exposure standard $\left(50 \mu \mathrm{g} / \mathrm{m}^{3}\right)$ for outdoor $\mathrm{PM}_{25}$ set by the Korean Ministry of Environment. Although a smoking ban had been imposed on internet cafes and pubs, smoking was still taking place in those locations. More stringent enforcement is required for the success of legal measures to protect patrons' and workers' health from second-hand smoke exposure. A ban on smoking in billiard halls should be introduced as soon as is feasible.
\end{abstract}

Keywords: ETS (Environmental Tobacco Smoke), internet café, billiard hall, $P M_{2.5}$.

\section{INTRODUCTION}

Environmental tobacco smoke (ETS) is produced by the smoking of cigarettes, pipe tobacco, cigars, etc., and results in second-hand smoke exposure. It is composed of mainstream smoke (MS) exhaled by the smoker and sidestream smoke (SS) generated at the end of a burning tobacco product. Passive smoking has been scientifically confirmed to lead to a variety of human diseases, disorders and deaths $[1,2]$.

ETS is important because it is one of the major pollutants that determine indoor air quality and because it contains approximately 60 kinds of substances confirmed or suspected to be human carcinogens, including nitrosamines, benzopyrenes, beta naphthylamine and polonium 210. It is estimated that $30 \%$ of all cancer deaths are caused by smoking, and second-hand smoke has been reported to contribute to a range of health effects such as lung cancer, cardiovascular disease and asthma [3]. Based on this, the US Environmental Protection Agency (EPA) classifies ETS as a Group A (known) carcinogen [4]. The US National Institute of Occupational Safety and Health has also designated ETS as a carcinogenic substance of the same grade as asbestos or benzene. In addition, tobacco smoke can easily diffuse and is difficult to remove, so a wide range of people become exposed to it irrespective of the intention of the smoker. On the basis of these risks, the US Centers for Disease Control and Prevention (CDC) is pursuing universal bans on smoking in public spaces such as workplaces, restaurants and pubs [5]. A large number of studies have been performed on indicator materials [6] to measure and evaluate airborne concentrations of ETS, which includes approximately 6,000 chemicals [7]. It is difficult to identify an indicator material with perfect 
conditions changing physically and chemically according to ETS generation time. The indicators with the greatest specificity for ETS exposure are 3-ethynyl pyridine and nicotine. However, because of the time and expense otherwise required for sample collection and analysis, $\mathrm{PM}_{2.5}$ (particulate matter with an aerodynamic diameter of less than $2.5 \mu \mathrm{m}$ ) is proposed as an indicator material by the World Health Organization (WHO) for its convenience [8].

A practical legislative effort is required to reduce the use of tobacco among young people with relatively high smoking rates under the auspices of the Framework Convention on Tobacco Control (FCTC) sponsored by WHO. As a result, the National Health Promotion Act in Korea prohibits smoking in a variety of public indoor environmental spaces such as in schools, internet cafes and restaurants. A smoking ban in hospitality facilities, including billiard halls as a small-scale sports facility, is gradually being expanded.

According to the National Health and Nutrition Examination Survey (2015), 39.3\% of male adults (aged 19 and over) in Korea smoke, although it is reported that this rate is gradually declining. In addition, this survey reported a smoking prevalence rate of $42.3 \%$ for men and $5.6 \%$ for women in the 10-19 age group, the third highest overall (Korea Center for Disease Control and Prevention) [9]. Young adults, i.e. those 19 to 24 years old, were 2.45 (95\% CI: $1.60,3.73)$ times more likely to smoke compared to people aged 65 and above [10]. It is very important for good health habits to be developed among the young since these habits are maintained throughout the lifespan and can greatly affect individual health. Also, the effectiveness of the progressive smoking ban policy at hospitality venues where it is being implemented must be ensured.

In this study, we estimated the level of second-hand smoke exposure by measuring $\mathrm{PM}_{2.5}$ as an indicator of ETS in internet cafes, pubs and billiard halls, all locations where young adults in their 20s spend a considerable amount of time, in the neighbourhood surrounding a university campus in Changwon, South Korea. We also evaluated the rate of implementation of smoking cessation at the internet cafes and pubs, which were designated as no-smoking areas by the National Health Promotion Act and investigate the necessity of smoking cessation for billiard halls not yet stipulated as smoke-free facilities.

\section{STUDY SUBJECTS AND METHODS}

\subsection{Study subjects}

This study covered 78 indoor spaces, including 20 internet cafes, 38 pubs (18 before regulation and 20 after) and 20 billiard halls within $3 \mathrm{~km}$ of the university campus for 3 months (between October and December) in 2014 (before legislation, 18 pubs) and the same 3 months in 2015 (after legislation, $n=60$ ). In the case of the pub, the same venues were selected before and after legislation.

\subsection{Study method}

2.2.1 Measurement of airborne $\mathrm{PM}_{2.5}$ ETS exposure characteristics were investigated by sampling $\mathrm{PM}_{25}$, an indicator of airborne ETS levels. The airborne $\mathrm{PM}_{2.5}$ concentrations in the indoor air were measured at a flow rate of $1.7 \mathrm{~L} / \mathrm{min}$ using a Sidepak real-time aerosol monitor (Model AM510, TSI Inc., Shoreview, MN 55126, USA), which is a light-scattering-type direct-reading device that determines mass concentration by scattering light with a wavelength of $670 \mathrm{~nm}$. Since the light-scattering 
method determines mass concentrations as a function of particle size and refractive index, the second-hand smoke concentration was calculated by applying a conversion factor of 0.295 to the indicated values [11-13]. In order to focus on particulate matter with a diameter of 2.5 $\mu \mathrm{m}$ or more, a $\mathrm{PM}_{2.5}$ impactor was attached to the SidePak and zero calibration was performed using a HEPA (high-efficiency particulate air) filter before sampling. The field researcher visited the hospitality venues between 7:00 pm and 11:00 pm on weekdays and measured the outdoor $\mathrm{PM}_{2.5}$ concentration for $5 \mathrm{~min}$ before and after the start of the indoor measurement at a representative point outside of the building. The indoor $\mathrm{PM}_{2.5}$ concentration was measured for 40 min by placing the SidePak on a table or chair that was not directly affected by $\mathrm{PM}_{2.5}$ sources, such as doors, windows and air conditioning. Samples were taken at 1-min intervals. The volume of the indoor space, the number of smokers and the ventilation conditions that could affect the concentration distribution during sampling were also recorded.

\subsubsection{Measurement and calculation of smoking density (SD)}

The number of smoked cigarettes and the number of fans installed in the venue for general ventilation were counted during the sampling period. The volume of the indoor venue was measured using a DLR130 (Robert Bosch Tool Corp., Mt. Prospect, Malaysia) [13]. The SD was calculated by the number of burning cigarettes per cubic meter of indoor volume, as shown in Equation (1).

$$
\text { Smoking Density }(\mathrm{SD})=\frac{\text { No. of burning cigarette }(\# \mathrm{bc})}{\text { Indoor volume }, \mathrm{m}^{3}}
$$

\subsubsection{Statistics and analysis}

$\mathrm{PM}_{2.5}$ concentrations were analysed using the TRAKPRO ${ }^{\mathrm{TM}}$ (version 4.6.10, TSI, USA) program. $\mathrm{PM}_{2.5}$ concentration was expressed in units of $\mu \mathrm{g} / \mathrm{m}^{3}$. The normality of $\mathrm{PM}_{2.5}$ concentrations distribution at indoor and outdoor air was tested by a Shapiro-Wilk test (W-test). Statistical analysis was performed using SPSS (ver. 23.0.0.0) and Microsoft Excel 2013, and the significance level ( $p$-value) was 0.05 . The cumulative probability plot distribution was obtained through SigmaPlot (ver. 10.0 for Windows, Systat Software, Inc., Chicago, IL, USA).

\section{RESULTS AND DISCUSSIONS}

\subsection{Smoking status and exposure levels of second-hand smoke}

As shown in Table 1, the smoking prevalence rates in three types of hospitality venues around a campus were $65 \%$ in internet cafes, $15.8 \%$ in pubs and $85 \%$ in billiard halls. In the case of the pubs and the internet cafes, although there were designated smoke-free areas from January 1, 2015 by the National Health Promotion Act, smoking was still taking place at the venues.

The smoking prevalence rate at the pubs in Changwon decreased from $33.3 \%(6 / 18)$ in 2014 to $10 \%$ (2/20) in 2015 with the introduction of the legislation. Kim et al. [7] reported a smoking rate in pubs in Changwon of $42 \%$ before the smoking ban legislation. However, billiard halls were not designated as smoking-free zones and showed the highest smoking rate among three kinds of facilities. Smoking was observed in eight pubs and 13 internet cafes, so more strict enforcement of the indoor smoking ban is necessary to improve indoor air quality. 


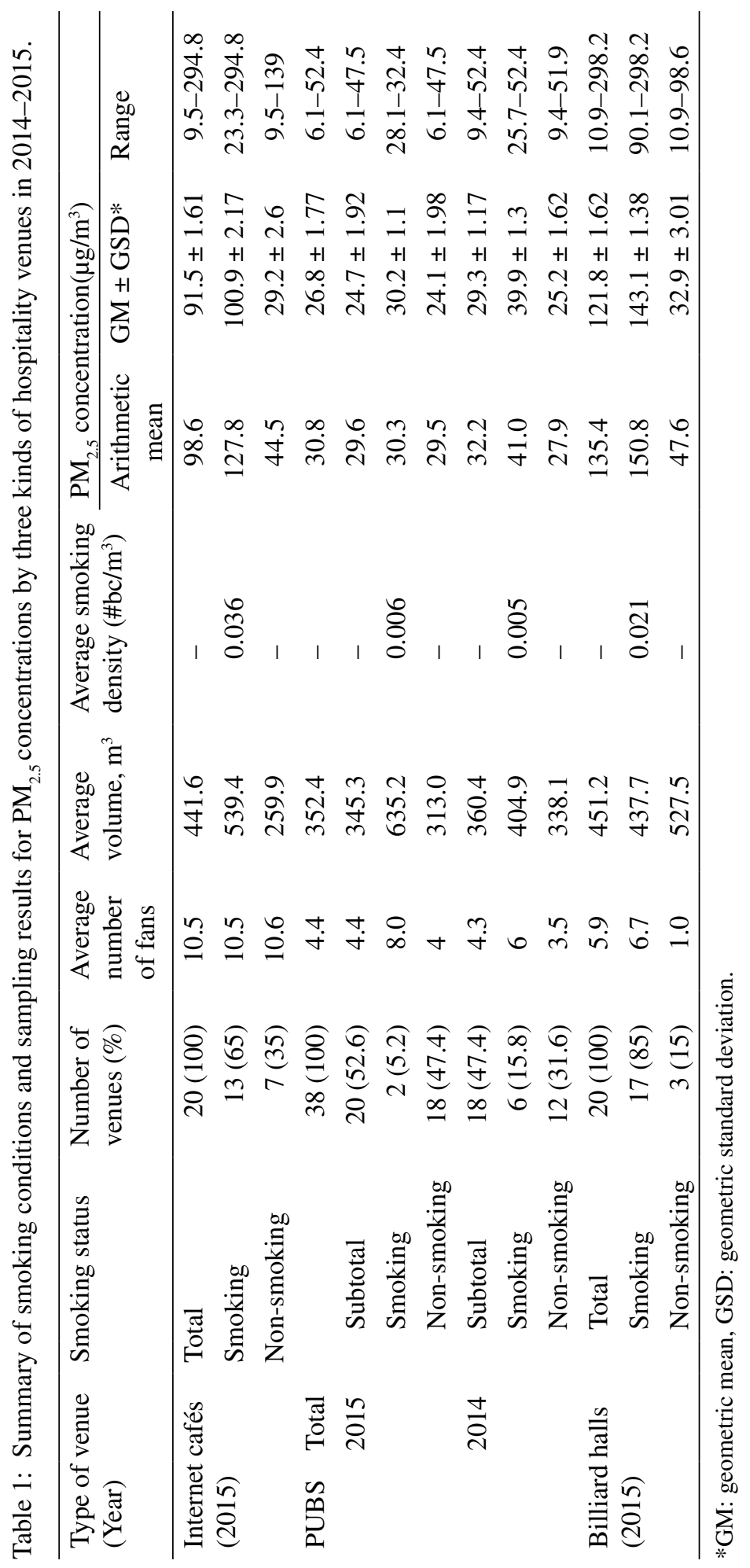


The distribution of $\mathrm{PM}_{2.5}$ concentrations in the indoor air for the three kinds of hospitality venue was a log-normal distribution by $\mathrm{W}$-test $(p<0.01)$. The cumulative probability plot of each facility is shown in Fig. 1 . The average $\mathrm{PM}_{2.5}$ concentrations were $135.4 \mu \mathrm{g} / \mathrm{m}^{3}$ (range $10.9-298.2 \mu \mathrm{g} / \mathrm{m}^{3}$ ) in billiard halls, $98.6 \mu \mathrm{g} / \mathrm{m}^{3}$ (range $9.5-294.8 \mu \mathrm{g} / \mathrm{m}^{3}$ ) in internet cafes and $30.8 \mu \mathrm{g} / \mathrm{m}^{3}$ (range $6.1-52.4 \mu \mathrm{g} / \mathrm{m}^{3}$ ) in pubs. There was a statistically significant difference in the distribution of $\mathrm{PM}_{2.5}$ concentrations among the three types of facilities $(p<0.001)$. The mean concentration of billiard halls was the highest, the highest concentration by venue was $298.2 \mu \mathrm{g} / \mathrm{m}^{3}$ in billiard halls and the lowest concentration by venue was $6.1 \mu \mathrm{g} / \mathrm{m}^{3}$ in pubs. The distribution of $\mathrm{PM}_{2.5}$ concentrations in billiard halls was about 4.4 times higher than that in pubs $(\mathrm{p}<0.001)$, and the difference between the highest and the lowest concentration was about 48.9 times. In a study conducted in 2014, before the smoking ban was enacted, the distribution of $\mathrm{PM}_{2.5}$ concentrations was measured as $180.4 \mu \mathrm{g} / \mathrm{m}^{3}$ (median, range 24.5$\left.273.1 \mu \mathrm{g} / \mathrm{m}^{3}\right)$ in internet cafes, $44.3 \mu \mathrm{g} / \mathrm{m}^{3}(3.0-116.2)$ in pubs, and $41.2 \mu \mathrm{g} / \mathrm{m}^{3}(23.2-241.0)$ in billiard halls [11]. There was a difference in the $\mathrm{PM}_{2.5}$ distributions between the internet cafes and the billiard halls both before and after the smoking control act.

The average concentrations for before (2014) and after (2015) the legislation were 32.2 (9.4-52.4) $\mu \mathrm{g} / \mathrm{m}^{3}$ and $29.6(6.1-47.5) \mu \mathrm{g} / \mathrm{m}^{3}$ in pubs. The ratio of indoor $\mathrm{PM}_{2.5}$ concentrations for these two time points was 0.92 for pubs. There was no statistically significant difference in the distribution of $\mathrm{PM}_{2.5}$ concentrations by year $(\mathrm{p}=0.120)$. Studies have shown that the indoor $\mathrm{PM}_{2.5}$ concentration decreases dramatically when an indoor smoking ban is properly implemented. In other countries, $\mathrm{PM}_{2.5}$ concentrations are generally reduced by $70 \%-90 \%$ when a comprehensive smoking prohibition policy is implemented [11, 13, 14], but Korea showed a lower reduction in $\mathrm{PM}_{2.5}$ concentrations after the ban. At 41 bars in Scotland, the $\mathrm{PM}_{2.5}$ concentration before the smoking cessation policy was $246 \mu \mathrm{g} / \mathrm{m}^{3}$, but the $\mathrm{PM}_{2.5}$ concentration was reduced by $86 \%$ to $20 \mu \mathrm{g} / \mathrm{m}^{3}$ after pertinent legislation [15]. The indoor $\mathrm{PM}_{2.5}$

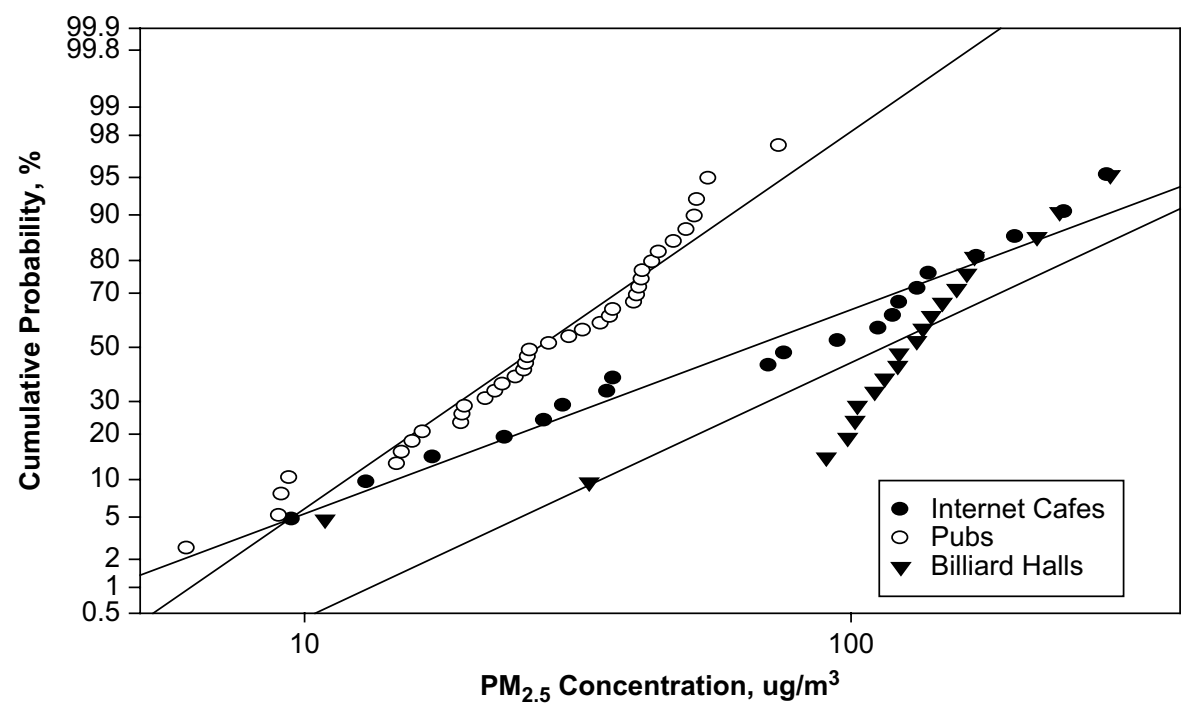

Figure 1: Comparison of the cumulative probability plots of $\mathrm{PM}_{2.5}$ concentrations for three kinds of hospitality venues. 


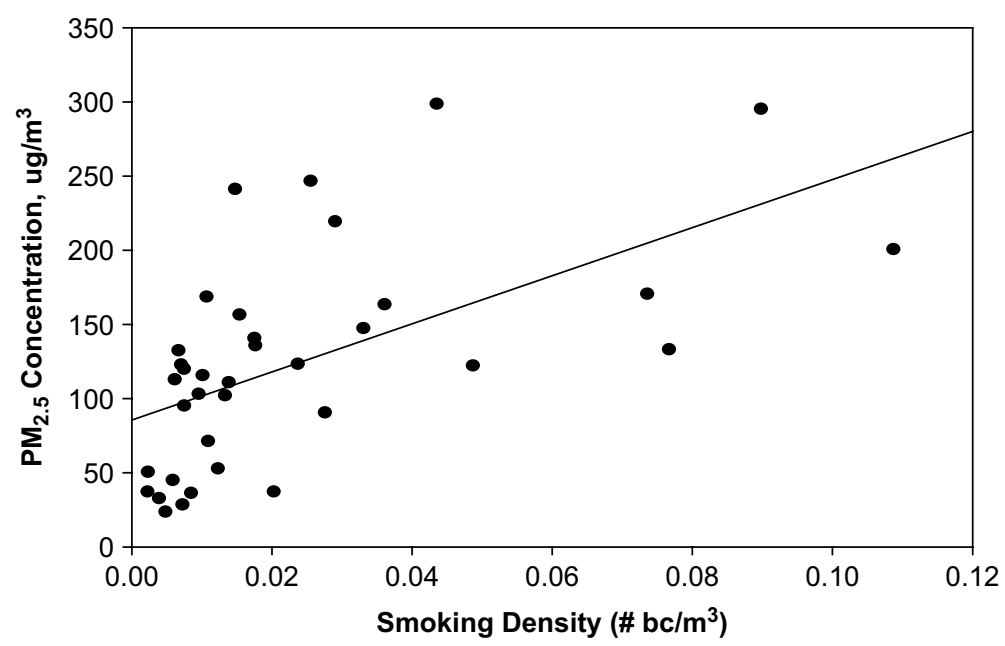

Figure 2: Regression analysis of $\mathrm{PM}_{2.5}$ levels and smoking densities in venues where smoking was observed $(y=85.6+1,621.1 x, r=0.58)$.

concentration in a sample of restaurants and bars $(\mathrm{n}=9)$ in Lexington, USA, was $199 \mu \mathrm{g} / \mathrm{m}^{3}$ before a smoking prohibition policy was introduced, but decreased to $91 \mu \mathrm{g} / \mathrm{m}^{3}$ after the legislation [11].

To determine the correlation between SD and $\mathrm{PM}_{2.5}$ concentrations in hospitality venues, correlation analysis was performed. The correlation coefficient was 0.58, as shown in Fig. 2. The relationship between indoor $\mathrm{PM}_{2.5}$ concentrations and SD in hospitality venues has been reported in previous studies. $\mathrm{PM}_{2.5}$ concentrations in 10 hospitality venues, including restaurant and pubs, in the United States tended to have a positive correlation with SD $(r=0.28$; $p=0.091$ ) [11]. In a study by Kim et al. [12], there was some correlation between SD and $\mathrm{PM}_{2.5}$ concentrations $(r=0.576, p<0.005)$. The distribution of $\mathrm{PM}_{2.5}$ concentrations is more correlated with SD than are other factors such as the number of guests or the ventilation system, which is probably due to the contribution of smoking to indoor distribution of $\mathrm{PM}_{2.5}$ concentrations. In previous studies, it has been reported that passive smoking contributes about $90 \%$ to $96 \%$ of respirable suspended particles in hospitality venues (casinos, bars, billiard halls) [11].

The concentration of $\mathrm{PM}_{2.5}$ was identified as the surrogate substance for best reflecting smoking condition. The average $\mathrm{PM}_{2.5}$ concentration in internet cafes with smoking allowed (13 of 20) was $127.8 \mu \mathrm{g} / \mathrm{m}^{3}$, which was statistically higher $(\mathrm{p}<0.05)$ than internet cafes where smoking was prohibited $\left(44.5 \mu \mathrm{g} / \mathrm{m}^{3}\right)$. In the case of billiard halls, the mean of $\mathrm{PM}_{25}$ concentrations in smoking venues was about three times higher than that of non-smoking venues. However, in the case of pubs, the significance of the statistical difference could not be confirmed.

In accordance with the FCTC proposed by WHO [8], cigarette smoking prevalence rates have been gradually decreasing in Korea as a result of the strengthening of smoking prohibition laws. In South Korea, the Korea Center for Disease Control and Prevention [9] reported that the rate of exposure to second-hand smoke among non-smokers declined to $57.9 \%$ in $2013,52.1 \%$ in 2014 and $35.4 \%$ in 2015 after the anti-smoking regulations were enacted for public areas. However, since billiard halls are classified as sports facilities rather than public 
places, only those billiard halls with a capacity of more than 1,000 people were targeted for smoking prohibition. Most billiard halls allow a much smaller numbers of occupants. Thus, most billiard halls are not yet subject to legal regulation and they show the highest concentration of $\mathrm{PM}_{2.5}$. There is a serious possibility of exposure to second-hand smoke. Therefore, in order to minimize the risks caused by second-hand smoke, related education and public outreach should be strengthened and the smoking ban policy should be extended to small sports facilities. When effectively enforced, smoking prohibition legislation is highly effective in improving indoor air quality and reducing the levels of indoor $\mathrm{PM}_{2.5}$ concentrations $[16,17]$. Strict enforcement and periodic monitoring play an important role in successful smoking prohibition practices. One avenue is to increase the penalties for smoking cigarettes in public places to reduce second-hand smoke through strong sanctions.

\subsection{Evaluation of air quality using AOI}

The US EPA has proposed an air quality index (AQI) using $\mathrm{PM}_{2.5}$ concentrations to predict the degree of air pollution [4]. According to this AQI, air quality is considered good in the range of $0-12.0 \mu \mathrm{g} / \mathrm{m}^{3}$, moderate at $12.1-35.4 \mu \mathrm{g} / \mathrm{m}^{3}$, unhealthy for sensitive groups at $35.5-55.4$ $\mu \mathrm{g} / \mathrm{m}^{3}$, unhealthy at $55.5-150.4 \mu \mathrm{g} / \mathrm{m}^{3}$, very unhealthy at $150.5-250.4 \mu \mathrm{g} / \mathrm{m}^{3}$ and hazardous for $250.5 \mu \mathrm{g} / \mathrm{m}^{3}$ or more. The indoor air quality in hospitality venues was assessed according to this AQI, and billiard halls $\left(135.4 \mu \mathrm{g} / \mathrm{m}^{3}\right)$ and internet cafes $\left(98.6 \mu \mathrm{g} / \mathrm{m}^{3}\right)$ averaged unhealthy levels assuming $24 \mathrm{~h}$ of exposure to $\mathrm{PM}_{2.5}$ concentration levels in indoor air. In the case of billiard halls and internet cafes where smoking is allowed, $6(35.3 \%)$ of 17 and

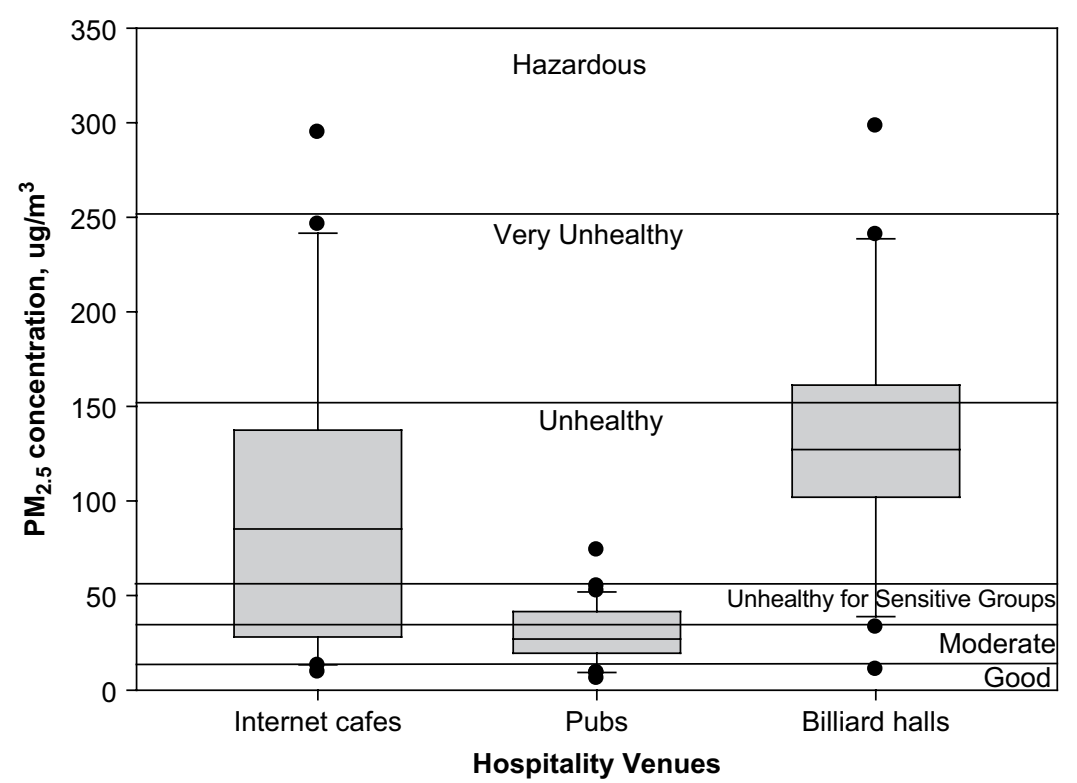

Figure 3: Assessment of indoor air quality depend on $\mathrm{PM}_{2.5}$ concentrations in internet cafes, pubs, and billiard halls, using 6 categories of the EPA AQI. Middle lines of boxes are median values; lower and upper bounds of boxes represent the $25^{\text {th }}$ and $75^{\text {th }}$ percentiles, respectively; whiskers represent the farthest data points within $10^{\text {th }}$ and $90^{\text {th }}$ percentiles, respectively; the individual data points are outliers. 
$4(30.8 \%)$ of 13 venues respectively exceeded $150.5 \mu \mathrm{g} / \mathrm{m}^{3}$, the very unhealthy level on the AQI. One internet cafe and one billiard hall were even evaluated as reaching the hazardous level, meaning immediate indoor environment improvement was required. Previous studies have also reported high concentrations of $\mathrm{PM}_{2.5}$ when allowing smoking in hospitality venues. The mean of $\mathrm{PM}_{2.5}$ concentrations $(\mathrm{n}=62)$ in smoking restaurants and pubs in Kentucky in the United States was $161 \mu \mathrm{g} / \mathrm{m}, 4.6$ times higher than the US ambient air quality standard [18].

The limitations of this study are as follows: First, $\mathrm{PM}_{2.5}$, the indicator applied for ETS, can be affected by a wide variety of sources other than tobacco smoke, including indoor and outdoor combustion, indoor activities, cooking, cleaning and more. Second, only pubs surrounding a college campus were selected for sampling, so it may be limited to representing only such pubs. However, the pubs were selected without any prior information about the presence of smokers and other factors influencing the indoor environment. Third, the availability of a ventilation system and the air exchange rate in the indoor environment were not taken into account for the distribution of particulate matter. Because the ventilation rate is a major determinant of indoor air quality, it is necessary to consider the type and principle of the ventilation system, air exchange rate and operating method. Fourth, the sampling result may be an underestimation because the sampling period overlapped with the time for end of term exams for students, which reduced the number of users of the venues. In order to accurately identify and confirm the reference value for each hospitality venue, the sample measurement period and the number of samples should be considered. In the future, it will be possible to improve public health by monitoring the status of second-hand smoke in these multi-use facilities, confirming the implementation rate of the smoking cessation policy, and strengthening the related regulations.

\section{CONCLUSION}

Hospitality venues such as internet cafes and pubs, which are frequently used by college students with high smoking rates, were included starting in January 2015 among areas where smoking is prohibited by the Korean National Health Promotion Act. Around 78 venues (18 venues overlapping), including internet cafes, pubs and billiard halls near a university campus, were assessed for their degree of implementation of the smoking prohibition policies over 3 months (October to December) in 2014 and in 2015, and ETS exposure levels were examined. The results of this study were as follows.

First, the smoking prevalence rate among these hospitality venues near the campus was the highest in billiard halls, where the smoking prohibition policy was not applied. Smoking was still taking place in the internet cafes or pubs despite the law (smoking prohibition) being implemented. Stricter smoking ban implementation is required for all internet cafes and pubs.

Second, the concentrations of $\mathrm{PM}_{2.5}$, the indicator substance for environmental tobacco smoke applied, were higher in the order of billiard halls. internet cafes and pubs. AQI evaluations showed that pubs maintained acceptable air quality, but most of the internet cafes and billiard halls were at a level harmful to health.

Third, in the case of internet cafes and pubs, the $\mathrm{PM}_{2.5}$ concentration levels of the venues allowing smoking were statistically higher than those in the venues where it was prohibited $(\mathrm{p}<0.05)$. According to legal regulations, the rate of smoking prohibition is increasing, and the distribution of $\mathrm{PM}_{2.5}$ concentrations in indoor air is also decreasing.

Fourth, in order to prevent passive smoking by visitors and employees and to protect public health, it is necessary to expand the scope of the National Health Promotion Act to billiard halls, where the concentrations of ETS were highest. 


\section{REFERENCES}

[1] Surgeon General of the United States, The Health Consequences of Involuntary Exposure to Tobacco Smoke: A Report of the Surgeon General. 2006-06-27. Retrieved 201207-24. Secondhand smoke causes premature death and disease in children and in adults who do not smoke, 2012.

[2] International Agency for Research on Cancer (IARC), IARC Handbooks of cancer prevention, tobacco control, Vol. 13: Evaluating the effectiveness of smoke-free policies. France, 2009.

[3] Barnoya, J. \& Navas-Acien, A., Protecting the World From Secondhand Tobacco Smoke Exposure: Where Do We Stand and Where Do We Go From Here? Nicotine \& Tobacco Research, 15(4), pp. 789-804, 2013.

[4] US Environmental Protection Agency (EPA), Federal Register, Vol 78, No. 10, Tuesday 15 January 2013, National Ambient Air Quality Standards for Particulate Matter, pp. 3085-3287, 2013.

[5] Center for Disease Control and Prevention (CDC). Smoke-free policies reduce smoking - Smoking \& tobacco use-smoking and tobacco use. Online, http://www.cdc.gov/ tobacco/data_statistics/fact_sheets/secondhand_smoke/protection/reduce_smoking (accessed 2 November 2016).

[6] Fu, M., Martinez-Sanchez, J. \& Galan, I., et al., Variability in the correlation between nicotine and $\mathrm{PM}_{2.5}$ as airborne markers of second-hand smoke exposure. Environmental Research, 127(1), pp. 49-55, 2013.

[7] Kim, B., Yun, D. \& Kim, S., Assessment of secondhand smoke exposure levels by measuring $\mathrm{PM}_{2.5}$ concentration at various smoking hotspot places inside and outside campus. Journal of the Korean Society for Research on Nicotine and Tobacco, 5(2), pp. 76-85, 2014.

[8] WHO Document Production Services, WHO Framework Convention on Tobacco Control. Online, http://apps.who.int/iris/bitstream/10665/42811/1/9241591013.pdf (accessed 10 November 2016).

[9] Korea Center for Disease Control and Prevention, Health statistics 2015: Korea National Health and Nutrition Examination Survey. Online, http://kostat.go.kr/wnsearch/ search.jsp (accessed 10 November 2016).

[10] Kim, S.R. Smoking prevalence and the association between smoking and sociodemographic factors using the Korea National Health and Nutrition Examination Survey data 2008 to 2010. Tobacco Use Insights 2012(5), pp. 17-26, 2012.

[11] Lee, K., Hahn E.J., Pieper, N., Okoli, C.T., Repace, J. \& Troutman, A., Differential impacts of smoke-free laws on indoor air quality. Journal of Environmental Health, 70(8), pp. 24-30, 2008.

[12] Kim, J., Lim, C., Lee, D., Kim, H., Guak, S., Lee, N., Kim, S., Ha, K. \& Lee, K., Indoor $\mathrm{PM}_{2.5}$ concentrations in different sizes of pubs with non-comprehensive smoke-free regulation. Journal of Environment and Health Science, 41(2), pp. 126-132, 2015.

[13] Ha K., Characteristics of ETS exposure in internet cafes, pubs, and pool halls around a university campus. WIT Transactions on Ecology and the Environment, Vol 215, WIT Press, 2018, ISSN 1743-3541.

[14] Goodman, P., Agnew, M., McCaffrey, M., Paul, G. \& Clancy, L., Effects of the Irish smoking ban on respiratory health of bar workers and air quality in Dublin pubs. American Journal of Respiratory and Critical Care Medicine, 175(8), pp. 840-5, 2007. 
[15] Semple, S., Creely, K.S., Naji, A., Miller, B.G. \& Ayres, J.G., Secondhand smoke levels in Scottish pubs: the effect of smoke-free legislation. Tobacco Control, 16(2), pp. 127-132. 2007.

[16] KHPF. Evaluation of effects of National smoke-free law by measuring indoor secondhand smoke. The Korea Health Promotion Fund, Ministry of Health \& Welfare, 2013.

[17] Azagba, S., Kennedy, R.D. \& Baskerville, N.B., Smoke-free school policy and exposure to second-hand smoke: A quasi-experimental analysis. Nicotine Tobacco Research. DOI:10.1093/ntr/ntv077. 2015.

[18] Lee, K., Hahn, E.J., Robertson, H.E., Lee, S., Vogel. S.L. \& Travers, M.J., Strength of smoke-free air laws and indoor air quality. Nicotine Tobacco Research, 11(4), pp. 381-6, 2009. 